\title{
Efecto reparador del suero autólogo en lesiones corneales producidas por agentes químicos. Ensayo preclínico aleatorio a doble ciego en conejos
}

\author{
Reparative effect of autologous serum in corneal injuries produced by chemical \\ agents. Random double-blind preclinical trial in rabbits
}

\author{
I. Hernández-Patiño ${ }^{1,6}$, G. Rossani' ${ }^{1}$ E. Borobio ${ }^{2}$, E. Talavera', M. Pilar Quiñones ${ }^{3}$, \\ R. Rozas LL ${ }^{4}$, Juan Carlos Roque ${ }^{1}$, M. Jara ${ }^{5}$, Jhony A. De la Cruz-Vargas ${ }^{1}$
}

\section{RESUMeN}

\begin{abstract}
El objetivo del estudio fue determinar el efecto reparador del suero autólogo en lesiones corneales de conejos producidas por agentes químicos. Se realizó un estudio piloto preclínico-experimental de caso-control con 10 unidades oculares obtenidas de cinco conejos. Las superficies corneales fueron lesionadas mediante abrasión quirúrgica controlada y posterior aplicación de alcohol al 70\% o ácido sulfúrico pH 1 (ácido de batería). Los casos fueron tratados con suero autólogo y los controles con suero fisiológico. Se siguió la evolución con fluoresceína y registro fotográfico inmediatamente después de producida la lesión, y a las 24, 48 y 72 horas. Los conejos fueron sacrificados y se hizo la evaluación histopatológica de las córneas. Los casos mostraron reducción significativa del perímetro de la lesión y mayor transparencia $(\mathrm{p}<0.008)$. Se observó diferencia significativa con relación a la progresión y calidad de tejido en el
\end{abstract}

\footnotetext{
${ }^{1}$ Instituto de Investigaciones en Ciencias Biomédicas, Facultad de Medicina Humana, Universidad Ricardo Palma, Lima, Perú

${ }^{2}$ Instituto de Ojos, - Clínica San Pablo, Lima, Perú

${ }^{3}$ Departamento de Anatomía Patológica del Hospital Nacional Edgardo Rebagliati Martins, Lima, Perú

${ }^{4}$ Laboratorio de Anatomía Patológica de la Universidad Ricardo Palma, Lima, Perú

${ }^{5}$ Escuela Profesional de Ciencias Veterinarias, Facultad de Ciencias Biológicas, Universidad Ricardo Palma, Lima, Perú

${ }^{6}$ E-mail: centrocamelias@gmail.com
}

Recibido: 4 de enero de 2021

Aceptado para publicación: 7 de octubre de 2021

Publicado: 22 de diciembre de 2021

CLos autores. Este artículo es publicado por la Rev Inv Vet Perú de la Facultad de Medicina Veterinaria, Universidad Nacional Mayor de San Marcos. Este es un artículo de acceso abierto, distribuido bajo los términos de la licencia Creative Commons Atribución 4.0 Internacional (CC BY 4.0) [https:// creativecommons.org/licenses/by/4.0/deed.es] que permite el uso, distribución y reproducción en cualquier medio, siempre que la obra original sea debidamente citada de su fuente original 
área lesionada $(\mathrm{p}<0.05)$. La evaluación histológica mostró un tejido corneal más uniforme y organizado en los casos. Se concluye que el suero autólogo presentó un mayor beneficio frente al uso del placebo en lesiones corneales producidas por estos agentes químicos.

Palabras clave: plasma rico en plaquetas, suero autólogo, conejos, lesiones corneales

\section{AbSTRACT}

The aim of this study was to determine the reparative effect of autologous serum on corneal lesions of rabbits produced by chemical agents. A preclinical-experimental case-control pilot study was carried out with 10 ocular units obtained from five rabbits. The corneal surfaces were injured by controlled surgical abrasion and subsequent application of $70 \%$ alcohol or sulfuric acid $\mathrm{pH} 1$ (battery acid). The cases were treated with autologous serum and the controls with physiological serum. The evolution was followed with fluorescein and photographic recording immediately after the injury occurred, and at 24, 48 and 72 hours. The rabbits were euthanised and the histopathological evaluation of the corneas was made. The cases showed a significant reduction in the perimeter of the lesion and greater transparency $(\mathrm{p}<0.008)$. A significant difference was observed in relation to the progression and quality of tissue in the injured area $(p<0.05)$. Histological evaluation showed a more uniform and organized corneal tissue in the cases. It is concluded that autologous serum presented a greater benefit compared to the use of placebo in corneal lesions produced by these chemical agents.

Key words: platelet-rich plasma, autologous serum, rabbits, corneal injuries

\section{INTRODUCCIÓN}

Las quemaduras oculares producidas por agentes químicos o físicos son una verdadera emergencia que genera un daño tisular en el globo ocular y/o estructuras anexas (Bradford, 2004). Al mismo tiempo, la mala cicatrización provocada por ulceración corneal constituye una de las principales causas de ceguera y de deterioro de la visión (Arenas y Torres, 2008). Se estima que cerca de 500000 lesiones oculares ocasionan ceguera a nivel mundial, donde el trauma es la causa principal unilateral (Geerling et al., 2004), con mayor frecuencia en adultos jóvenes que se encuentran dentro de la población económica productiva (Ministerio de Salud, 2009), donde dos terceras partes ocurren en el trabajo y el resto por accidentes domésticos (Díaz-Mendoza et al., 2019). Hospitales de
España, Francia, Reino Unido y Estados Unidos reportan entre 5 a $8 \&$ de las emergencias atendidas (Edwards, 1987; Nash y Margo, 1998; Girard et al., 2002; Sánchez et al., 2004). $\mathrm{n}$ estos casos, las producidas por álcalis son dos veces más frecuentes que las producidas por ácidos, debido a que son muy usados en el hogar y las industrias (Kanski, 2008).

Según el informe del Boletín del Anuario Estadístico mensual de notificaciones de accidentes de trabajo, incidentes peligrosos y enfermedades ocupacionales del ministerio del trabajo y promoción del empleo del Perú de junio del 2020 (MTPE, 2020), las lesiones oculares ocupan el primer lugar con 10.2\% en los cuadros de partes del cuerpo lesionadas. Asimismo, según el departamento de estadística del Instituto Nacional de Oftalmología (INO), las lesiones oculares que afec- 
taron la córnea hasta el tercer trimestre de 2019 bordearon los 12700 casos, ocupando el tercer lugar de frecuencias de atenciones (INO, 2019).

Las lesiones oculares se pueden clasificar según su agente causal, en quemaduras químicas generadas por álcalis o ácidos y quemaduras físicas por agentes térmicos o radiación ultravioleta (Dua et al., 2001; Spector y Fernández, 2008) y la severidad del daño ocular, ya sea producido por álcali o acido, se determina por el tipo de químico, la concentración de la solución, la superficie de contacto, la duración de exposición y grado de penetración (Gandaho et al, 2016). Una vez producida la lesión se manifiestan signos y síntomas como dolor, epifora, fotofobia, llegando inclusive a necrosis de la córnea, isquemia del limbo y hasta complicaciones como opacidad de la córnea y ceguera (Nishida et al., 1996).

El suero autólogo no solo actúa como lubricante en la superficie ocular, sino que también proporciona varias sustancias esenciales para la recuperación del epitelio dañado, incluida la vitamina A, el factor de crecimiento epidérmico (EGF), la fibronectina y una variedad de citocinas (Tsubota et al., 1999; Vercesi et al., 2009). Estos factores de crecimiento tisular en el suero se facilita la proliferación, migración y diferenciación del epitelio de la superficie ocular (Acosta et al., 2014).

Tsubota et al. (1999), al evaluar la efectividad del suero autólogo en 20 pacientes demostraron que las gotas oftálmicas de plasma rico en plaquetas (PRP) reducían la recidiva de erosiones corneales sin complicaciones significativas. Asimismo, Vercesi et al. (2009), demostraron en conejos que la utilización del uso tópico de factores de crecimiento puede constituirse en una herramienta útil para el manejo de úlceras de córnea de difícil tratamiento, en tanto que Acosta et al. (2014) concluyeron que el PRP demostró ser tan efectivo como el producto comercial Solcosery $l^{\mathrm{R}}$ para el tratamiento de regenera- ción de úlceras corneales profundas y extensas.

La solución de las lesiones que afectan la superficie ocular constituye un problema de salud pública a resolver, puesto que el tratamiento convencional no siempre permite una evolución favorable. Debido a la evidencia científica que demuestra que los factores de crecimiento mejoran la cicatrización de tejidos blandos con epitelios muy parecidos a los originales, el presente estudio tuvo como objetivo determinar mediante un estudio piloto en conejos el efecto del Suero Autólogo (SA) rico en factores de crecimiento aplicado en estas lesiones traumáticas de la superficie corneal de evolución lenta e incierta, evaluando el tiempo de recuperación al inducir mejor cicatrización, la calidad del tejido resultante y las complicaciones infecciosas propias de estas lesiones.

\section{MATERIALES Y MÉTODOS}

\section{Lugar del Estudio}

Se realizó un estudio piloto preclínico experimental de caso-control, aleatorio y enmascarado en todas sus etapas en lesiones de $15 \mathrm{~mm}^{2}$ en córneas de conejos producidas por abrasión quirúrgica controlada y posterior contacto al alcohol o ácido sulfúrico $\mathrm{pH}$ 1 (ácido de batería), en los laboratorios de la Universidad Ricardo Palma, Lima.

\section{Animales y Tratamientos}

Se trabajó con 10 unidades oculares provenientes de cinco conejos jóvenes machos (Oryctolagus cuniculus), raza Nueva Zelanda, de peso $2.5 \pm 0.5 \mathrm{~kg}$, provenientes del bioterio del Instituto Nacional de Salud (INS). Los conejos, previo al estudio, recibieron aclimatación por una semana en jaulas individuales. Se les proporcionó alimento y agua ad libitum en una habitación con temperatura controlada $\left(21 \pm 5^{\circ} \mathrm{C}\right)$, manteniendo ciclos de 12 horas de luz y 12 horas de oscuridad. 
Los especímenes se distribuyeron en dos grupos: A (dos conejos -4 unidades oculares) a quienes se les aplicó alcohol al $70 \%$ en los ojos; B ( 3 conejos -6 unidades oculares) a quienes se les aplicó ácido sulfúrico pH 1. La aplicación abrasiva, en todos los casos fue en un ojo, dejando el otro ojo como control (caso-control), donde se aplicó suero fisiológico (SF). El enmascaramiento se dio por parte de las evaluaciones oftalmológicas y las de anatomía patológica, quienes desconocían las unidades caso-control.

Las variables de estudio fueron: la evaluación del dolor durante la etapa de estudio con la escala de la mueca del conejo - Rabbit Grimace Scale - RbtGS - (Benato et al., 2020) que arroja una puntuación de 0 (no presente), 1 (moderadamente presente) y 2 (obviamente presente); evolución del área de la lesión con la prueba de fluoresceína; transparencia corneal y fotografía en macro; aparición de infecciones; y evaluación histopatológica de las muestras corneales post mortem.

\section{Procedimientos}

La anestesia fue de acuerdo con la clasificación ASA 2. Se utilizó Propofol 5-14 mg $/ \mathrm{kg}$ EV, para el manejo del dolor se utilizó Ketamina $15-20 \mathrm{mg} / \mathrm{kg}$ EV y para revertir el efecto de la sedación se usó Yohimbina 0.2$1 \mathrm{mg} / \mathrm{kg}$ EV. Los fármacos fueron aplicados a través de la vena auricular marginal.

El Suero Autólogo (SA) se extrajo bajo técnica cerrada al vacío con nula manipulación, según la normativa española, mediante el Real Decreto 175/2001 (BOE N. ${ }^{\circ} 065-2001$ de 16/03/2001: 9746-9755). La sangre (10 ml) se colocó en seis tubos estériles al vacío de $3.5 \mathrm{ml}$ con citrato de sodio $3.2 \%$, los que se sometieron a centrifugación (Greed-Med GT $119-100 \mathrm{~T}$ ) a $3500 \mathrm{rpm}$ durante $8 \mathrm{~min}$. Se obtuvo de 5 a $7 \mathrm{ml}$ de $\mathrm{SA}$ acondicionados en goteros y se almacenaron a $4{ }^{\circ} \mathrm{C}$ para su aplicación durante los siguientes 5 días. Cada frasco podía contener entre 100 y 140 gotas.
La lesión corneal controlada se dio el Día 0 en las instalaciones del laboratorio de cirugía experimental de la Escuela Profesional de Ciencias Veterinarias de la de la Universidad Ricardo Palma. Se hizo, de manera controlada, una laceración superficial con un bisturí $11^{\circ}$ en un área aproximada de $50 \mathrm{~mm}^{2}$, con posterior lavado con solución fisiológica y limpieza con lactantes de celulosa para eliminar restos. La aplicación inmediata de los agentes agresores (alcohol y ácido sulfúrico) fue de manera aleatoria bajo el mismo periodo anestésico.

Pasados 30 segundos, se realizó el lavado con SF (Cuadro 1). Las gotas oftálmicas con SA y SF fueron aplicadas en la unidad caso y en la unidad control, respectivamente. Desde el día 0 hasta el día 2 se les aplicó una gota cada 2 h y del día 3 al 4 una gota cada $4 \mathrm{~h}$. La primera dosis se hizo a las 2 horas de la lesión (Cuadro 1). Todos los casos y controles recibieron un total de 36 gotas oftálmicas de suero autólogo y de suero fisiológico respectivamente. La dosificación de las gotas oftálmicas en condiciones normales y fuera del periodo de la anestesia se hizo sin generar estrés en los animales.

Todas las evaluaciones fueron realizadas por el mismo oftalmólogo, y se efectuaron antes del procedimiento, a las 2 horas de producida la lesión y se continuó con una evaluación diaria hasta el día 4. En el día 5 y luego del sacrifico de los animales, se extrajeron los ojos y se procedió al aislamiento de las corneas para su inmediato traslado al laboratorio donde las córneas extraídas se fijaron en formol al 10\% para su tinción e inclusión en hematoxilina-eosina y cortes de 14 $\mu \mathrm{m}$. Para la evaluación histopatológica, un juego de muestras se analizó en el Laboratorio de Anatomía Patológica de la Facultad de Medicina de la Universidad Ricardo Palma, y un segundo set de láminas en el Departamento de Anatomía Patológica del Hospital Nacional ESSALUD - Edgardo Rebagliati Martins. 
Cuadro 1. Secuencia de las actividades realizadas en el ensayo preclínico

\begin{tabular}{|c|c|c|c|c|}
\hline $\begin{array}{lc}\text { Periodo de } & \text { Aleatorización } \\
\text { adaptación } & \text { de grupos }\end{array}$ & Día 0 & Días (0-1-2) & Días (3-4) & $\begin{array}{c}\text { Final del } \\
\text { estudio }\end{array}$ \\
\hline 07 días & $\begin{array}{c}\text { Evaluación ocular } \\
\text { (Equipo de } \\
\text { oftalmología) } \\
\text { Preparación del suero } \\
\text { autólogo } \\
\text { (Equipo de } \\
\text { INGECEL) }\end{array}$ & $\begin{array}{l}\text { Frecuencia } \\
(\text { Cada } 2 \mathrm{~h}) \\
\text { (Equipo de } \\
\text { veterinaria) }\end{array}$ & $\begin{array}{l}\text { Aplicación de } \\
\text { suero autólogo } \\
\text { y lágrimas } \\
\text { artificiales } \\
\text { Frecuencia } \\
\text { (Cada } 2 \text { h) } \\
\text { (Equipo de } \\
\text { veterinaria) }\end{array}$ & $\begin{array}{l}\text { Preparación } \\
\text { anestésica de } \\
\text { los conejos } \\
\text { (Equipo de } \\
\text { veterinaria) }\end{array}$ \\
\hline \multirow[t]{2}{*}{$\begin{array}{c}\text { Periodo de } \\
\text { acondicionamiento y } \\
\text { evaluación de los conejos } \\
\text { (Evaluación ocular) }\end{array}$} & $\begin{array}{c}\text { Preparación anestésica } \\
\text { de los conejos } \\
\text { (Equipo de } \\
\text { veterinaria) }\end{array}$ & \multirow{2}{*}{\multicolumn{2}{|c|}{$\begin{array}{c}\text { Registro diario de la evolución de } \\
\text { los conejos } \\
\text { (Equipo de INICIB) }\end{array}$}} & $\begin{array}{l}\text { Sacrificio y } \\
\text { enucleación de } \\
\text { los ojos } \\
\text { (Equipo de } \\
\text { veterinaria) }\end{array}$ \\
\hline & $\begin{array}{c}\text { Lesión ocular } \\
\text { mecánica en todas las } \\
\text { unidades oculares de } \\
\text { los conejos } \\
\text { (Equipo de } \\
\text { oftalmología) }\end{array}$ & & & $\begin{array}{l}\text { Preparación y } \\
\text { estudio de las } \\
\text { muestras } \\
\text { oculares } \\
\text { (Equipo de }\end{array}$ \\
\hline $\begin{array}{l}\text { Marcación, distribución y } \\
\text { acondicionamiento de los } \\
\text { conejos de manera aleatoria }\end{array}$ & $\begin{array}{l}\text { Aplicación de agentes } \\
\text { químicos: Alcohol } \\
90 \% \text { y Ácido. de } \\
\text { batería } \\
\text { (Equipo de } \\
\text { oftalmología) }\end{array}$ & \multicolumn{2}{|c|}{$\begin{array}{l}\text { Evaluación ocular diaria } \\
\text { Test de fluoresceína } \\
\text { (Equipo de oftalmología) }\end{array}$} & $\begin{array}{c}\text { anatomía } \\
\text { patológica) } \\
\text { Reporte } \\
\text { histopatológico } \\
\text { de las muestras }\end{array}$ \\
\hline $\begin{array}{c}\text { Grupo A (Alcohol 70\%) y } \\
\text { Grupo B (Ácido de batería } \\
\text { pH 1) }\end{array}$ & $\begin{array}{l}\text { Evaluación ocular } \\
\text { post lesión y lavado } \\
\text { con suero fisiológico } \\
\text { (Equipo de } \\
\text { oftalmología) } \\
\text { Supervisión y } \\
\text { (Equi }\end{array}$ & $\begin{array}{l}\text { vigilancia de los c } \\
\text { po de veterinaria) }\end{array}$ & conejos & $\begin{array}{l}\text { Informe final } \\
\text { del estudio } \\
\text { piloto }\end{array}$ \\
\hline
\end{tabular}

\section{Análisis Estadístico}

Los datos recolectados se registraron a doble ciego en una hoja de Excel 2017 contrastándola con las hojas de recolección de datos para evitar la omisión o el ingreso de datos erróneos. Se le asignó un código a cada unidad de trabajo. Las variables cualitativas se describieron a través de frecuencias y porcentajes. Para el análisis de la normalidad se utilizó la prueba de Shapiro-Wilk y la prueba U de Mann-Whitney. Para el análisis bivariado se utilizó la prueba Exacta de Fisher - función hibrida para variables politómica disponible en el software Stata $(\mathrm{p}<0.05$, IC del 95\%). 

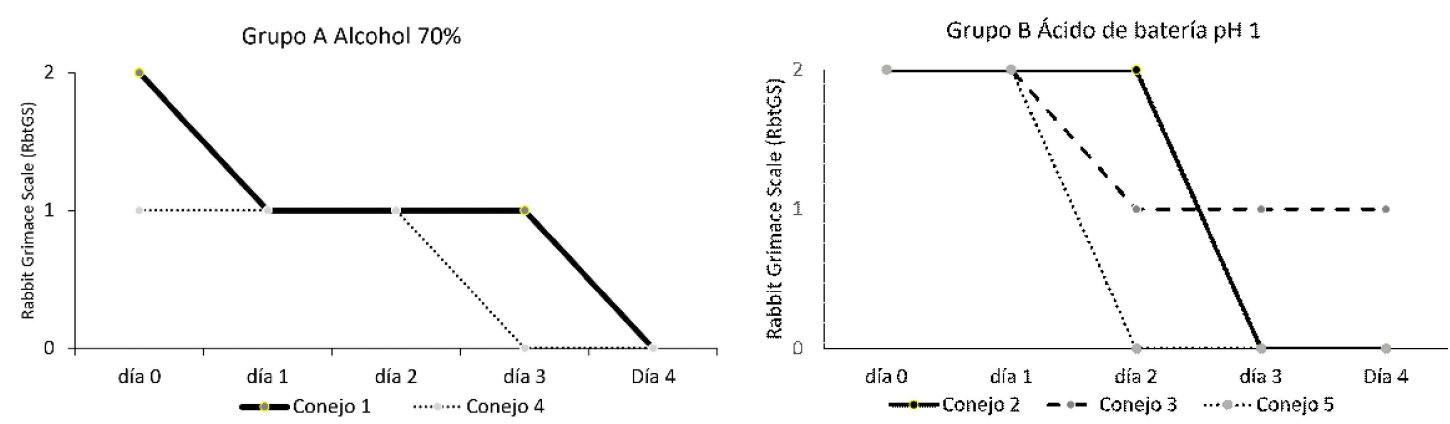

Figura 1. Escala de muecas de conejo después de una agresión ocular con alcohol $70 \%(n=2)$ o ácido sulfúrico $\mathrm{pH} 1(\mathrm{n}=3)$ en conejos medida cada $24 \mathrm{~h}$

\section{Aspectos Éticos}

El estudio fue aprobado por el Comité de Ética de Estudios en Animales de la Universidad Ricardo Palma (URP). Los procedimientos estuvieron de acuerdo a las normas de la Asociación para la Investigación en Visión y Oftalmología (normas ARVO) relacionadas con el uso de animales en investigación.

\section{Resultados}

\section{Escala de la Mueca del Conejo (RbtGS)}

El tipo de agente agresor tuvo efectos significativos sobre la puntuación RbtGS. El ácido sulfúrico pH 1 fue más «doloroso» para el animal que el alcohol (Figura 1). Esta última se vio reflejada en el bienestar de los animales a partir de las dos horas de la intervención. Todos los conejos disminuyeron progresivamente su malestar hasta el día 4, excepto un espécimen del Grupo B que mantuvo un malestar moderadamente presente hasta el final del estudio (Figura 2).

\section{Test de Fluoresceína (Efecto Reparador)}

Los ojos tratados con SA (Figura 3) mostraron reducción significativa del perímetro de la lesión y mayor transparencia $(p<0.008)$. Asimismo, se observa que el tratamiento con SA promovió una reparación más eficiente que los tratados con $\mathrm{SF}(\mathrm{p}<0.05)$ (Cuadro 2).

Al analizar el promedio de reducción de las lesiones corneales se encontró que el grupo que recibió el SA tuvo una reducción porcentual significativamente más rápida que los del grupo control ( $p=0.005$ de U de MannWhitney). El total de casos tuvo un porcentaje de reducción del $85.2 \%$ a diferencia del porcentaje de reducción de los controles que fue del $47.4 \%$ (Cuadro 3).

\section{Estudio Histopatológico}

Las muestras histopatológicas teñidas con hematoxilina-eosina fueron analizadas por dos patólogos ajenos al estudio. El daño del epitelio corneal mostró ser similar para ambos agentes agresores (ácido sulfúrico $\mathrm{pH} 1$ o alcohol 70\%). En ambos casos se encontró un tejido conjuntivo hialino con células fusiformes de aspecto fibroblaìstico, estroma laxo con zonas basófilas y presencia de leve infiltrado inflamatorio. 

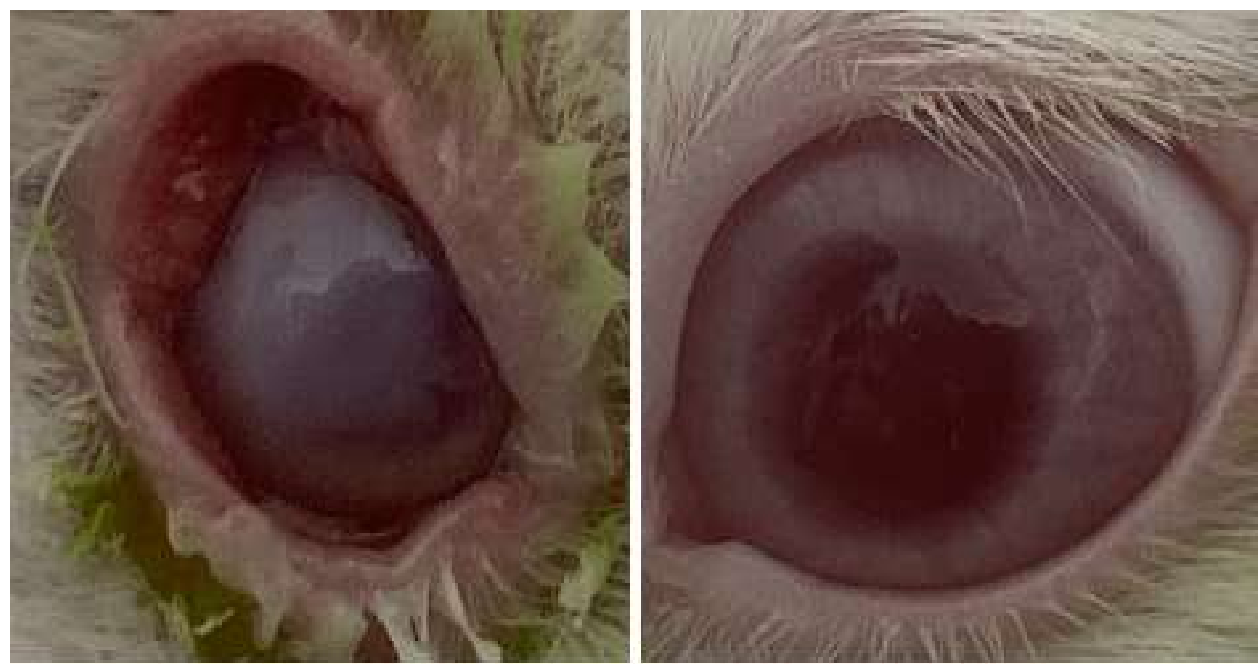

Figura 2. Lesión corneal producida en conejo por desepitilización controlada más agente agresor (ácido de batería pH 1). Evaluación de la opacidad corneal al día 3. Izquierda: Ojo tratado con suero fisiológico con presencia de secreción alrededor del ojo. Derecha: Ojo tratado con suero autólogo, con mejora en la opacidad corneal sin secreciones alrededor del ojo

La córnea de los conejos tratados con SA al día 4 mostró un epitelio corneal uniforme, no discontinuo. La membrana de Bowman se encuentra visible. El estroma laxo con formaciones basófilas con un leve infiltrado inflamatorio local. La membrana de Descemet y el endotelio corneal se encuentran conservados. En las córneas control se observó discontinuidad del epitelio corneal, degeneración vacuolar epitelial e hiperplasia papilar con pequeñas cavidades dilatadas de aspecto quístico y neovascularización, además de inflamación aguda con presencia de infiltrado polinuclear de aspecto leucocitario e inflamación crónica con presencia mononuclear de aspecto linfocitario (Figura 4).

\section{Discusión}

Se vienen desarrollando técnicas y tratamientos dirigidos a favorecer la regeneración de los tejidos corneales, entre ellos el concentrado Autólogo de Plaquetas (Bonilla-
Gutierrez et al., 2017). En el presente estudio se utilizó el suero autólogo generado de la extracción proceso de centrifugación, debido a que dentro del suero se encuentra diversas proteínas que intervienen en la reparación, pero que no estarían involucradas dentro del plasma rico en plaquetas, lo que podría explicar los resultados obtenidos en comparación con otros reportes.

En la reparación tisular se llevan a cabo complejos procesos en los que intervienen multitud de factores, entre ellos células, proteínas y citoquinas. Las plaquetas y sus agentes son columnas importantes en la construcción del entramado que restaura las heridas (Borzini y Mazzucco, 2007). Los factores de crecimiento contenidos en el SA son útiles y de demostrada eficacia en determinadas patologías oftalmológicas, como es el caso de las úlceras corneales, el síndrome de ojo seco, el síndrome post-LASIK, la perforación ocular, la disfunción de la glándula lagrimal, los agujeros maculares y los trasplantes de lim- 


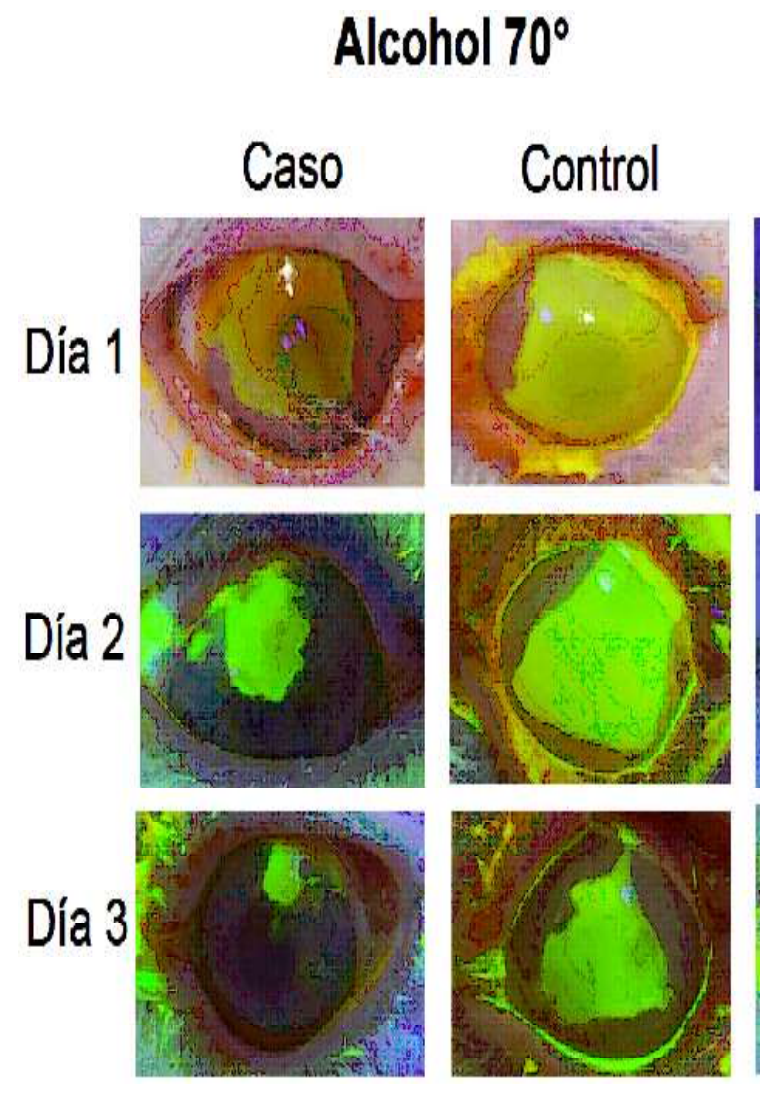

\section{Ac. de bateria pH2}

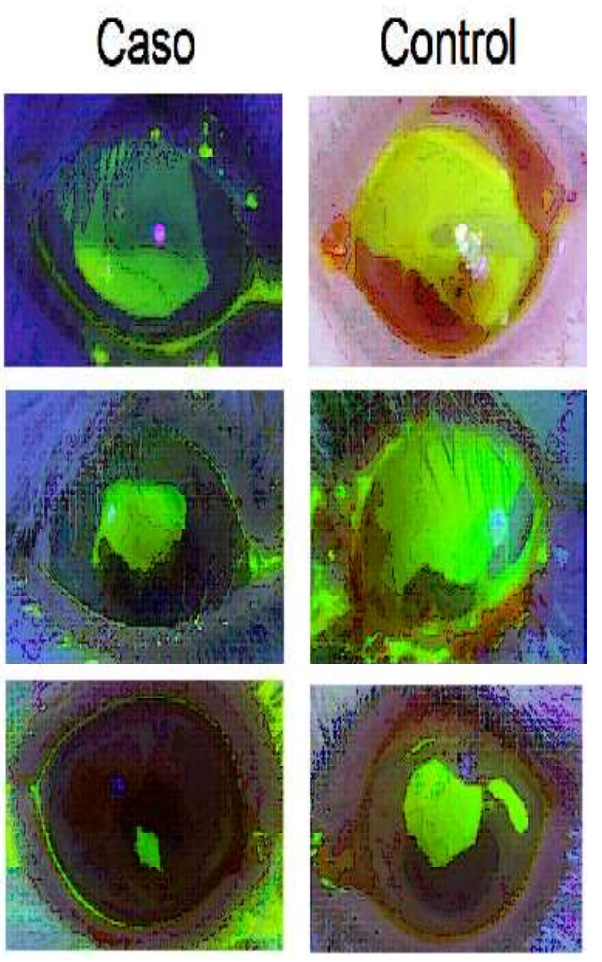

Figura 3. Evolución de la lesión epitelial producida experimentalmente en ojos de conejos según tipo de agente agresor (alcohol 70\%, ácido de batería pH 1 ). Las imágenes muestran que el suero autólogo promueve una cicatrización de la herida corneal más rápida y con un tejido de mejor calidad

Cuadro 3. Reducción porcentual del tamaño de las lesiones corneales en conejos sujetos experimentalmente a agresiones con alcohol $70 \%$ o ácido de batería pH1 y tratados con suero autólogo (SA) o suero fisiológico (SF)

\begin{tabular}{lcccc}
\hline Tipo de lesión & $\begin{array}{c}\text { Caso (SA)/ } \\
\text { control (SF) }\end{array}$ & Día 1 & Día 2 & Día 3 \\
\hline \multirow{2}{*}{ Alcohol 70 } & SA & $143.1 \pm 11$ & $70.8 \pm 28.1$ & $37.1 \pm 20.6$ \\
& SF & $152.5 \pm 4.1$ & $98.9 \pm 16.5$ & $67.2 \pm 31.7$ \\
Ácido de batería & SA & $117.9 \pm 27.2$ & $57.7 \pm 24.7$ & $28.9 \pm 20.6$ \\
pH 1 & SF & $140.1 \pm 16.5$ & $117.6 \pm 27.2$ & $82.5 \pm 23.1$ \\
\hline
\end{tabular}

Existe diferencias significativas entre las lesiones tratadas con SA y las lesiones tratadas con SF con relación a la reducción porcentual de la lesión ( $p=0.005)$. (Prueba U de Mann-Whitney) 

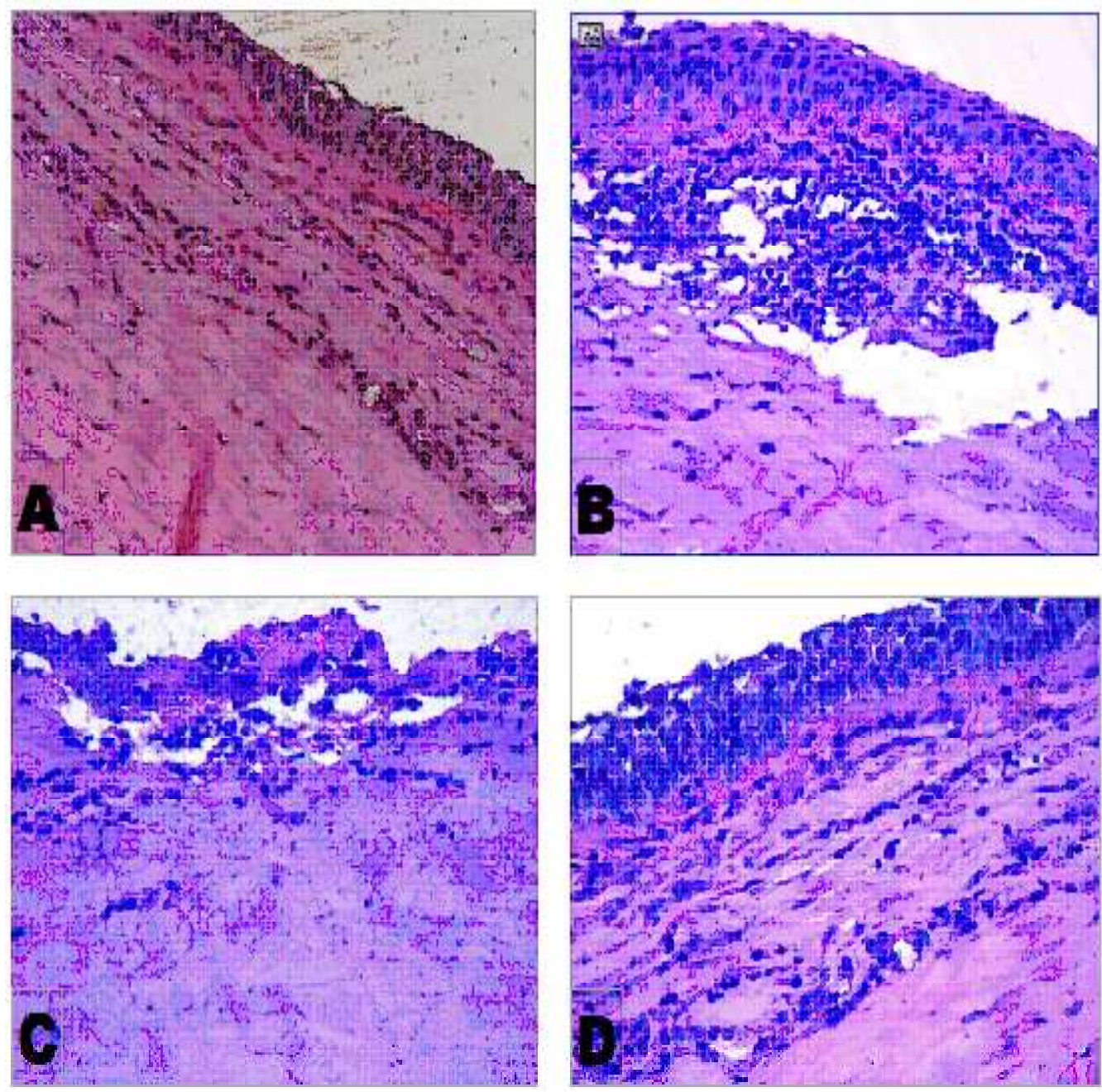

Figura 4. Cortes con hematoxilina y eosina de córneas de conejos durante el proceso de cicatrización. A-B: Córneas laceradas y expuestas al agente agresor alcohol 70\%; C-D: Córneas laceradas y expuestas al agente agresor ácido de batería pH 1. A: Córnea derecha (20X) tratada con suero autólogo. Queratitis crónica, estroma laxo con leve infiltrado inflamatorio. B: Cornea izquierda (20X) no tratada. Tejido conjuntivo hialino con estructuras papilares con pequeñas cavidades dilatas de aspecto quístico con infiltrado inflamatorio agudo y crónico. C: Córnea derecha (20X) no tratada. Degeneración vacuolar epitelial e hiperplasia papilar, fibrosis, ulcera con inflamación aguda. D: Córnea izquierda (20X) tratada con suero autólogo. Queratitis crónica, estroma laxo con áreas basófilas en cantidad moderada

bo (Solans Pérez et al., 2015). En este sentido, Montón-Echevarría et al. (2007) concluyen que la utilización de los factores de crecimiento incrementa la reparación de tejidos blandos, disminuyendo las infecciones concomitantes, las postoperatorias y el dolor.
En la búsqueda de alternativas a los agentes químicos presentes en las lágrimas artificiales se encontró que el SA tiene el mismo $\mathrm{pH}$ y osmolaridad de la lágrima (Geerling et al., 2004). Esto en parte explicaría la tolerancia y rápida adaptación del empleo del SA 
en el presente estudio. No obstante, existen reportes de estudios comparativos en otros animales donde no se encontró diferencias significativas entre el grupo caso y control en el marco de la opacidad y reparación de la córnea (Vercesi et al., 2009; Acosta, 2017).

Si bien es cierto, los hallazgos del presente estudio son prometedores y se viene manejando parámetros estandarizados de procesos en la obtención, aplicación y concentraciones de suero autólogo, no existe un consenso hasta el momento en referencia a este tema. Se utilizó SA al 100\% sin manipulación alguna de tejidos con un solo ciclo de centrifugación y con aplicación de 1 gota cada dos horas con disminución progresiva de la dosis. Otros autores manifiestan diferencias en las concentraciones y goteo en el tiempo, incluso que la concentración de este debería ser al 20\% (Young et al., 2004; Vercesi et al., 2009; Acosta, 2017). En esta línea, en este estudio se optó por no utilizar coadyuvantes como analgesia o antibióticos de dosificación ocular sin que se hayan desarrollado procesos infecciosos agregados, a diferencia de otros estudios (Noble et al., 2004; Young et al., 2004).

\section{Conclusiones}

- El tratamiento con suero autólogo promueve una reparación de las lesiones corneales de manera más eficiente que los tratados con suero fisiológico.

- El estudio histopatológico mostró una mejor distribución, regeneración y conservación de las capas cornales con el uso del suero autólogo.

\section{Literatura Citada}

1. Acosta A. 2017. Comparación del efecto terapéutico del suero autólogo y el efecto epitelizante ocular en el tratamiento de úlceras corneales grado II en cani- nos braquiocefálos. Tesis de Médico Veterinario Zootecnista. Ecuador: Univ. Técnica de Ambato. $54 \mathrm{p}$.

2. Acosta L, Castro M, Fernandez M, Oliveres E, Gomez-Demmel $E$, Tartara L. 2014. Treatment of corneal ulcers with platelet rich plasma. Arch Soc Esp Oftalmol 89: 48-52. doi: 10.1016/ j.oftal.2013.09.002

3. Arenas E, Torres LK. 2008. Nuevo método para el tratamiento de úlceras corneanas. Rev Soc Col Oftal 41:570-579.

4. Benato L, Murrell J, Blackwell E, Saunders R, Rooney N. 2020. Pain and analgesia in pet rabbits: a survey of the attitude of veterinary nurses. J Small Anim Pract 61: 576-581. https://doi.org/ 10.1111/jsap. 13186

5. Bonilla-Gutierrez, AF, Aragon-Urrego C, Aristizabal-Paez OL. 2017. Protocolo para la obtención de un concentrado autólogo de plaquetas en conejos: estudio piloto. Rev Med Vet Zoot 64: 2431. doi: 10.15446/rfmvz.v64n1.65813

6. Borzini P, Mazzucco I. 2007. Plateletrich plasma (PRP) and platelet derivatives for topical therapy. What is true for the biological view point? ISBT Sci Series 2: 272-281.

7. Bradford C. 2004. Basic ophthalmology: Essentials for medical students. $8^{\text {th }}$ ed. San Francisco, USA: American Academy of Ophthalmology. 219 p.

8. Díaz-Mendoza JJ, Chirinos-Saldaña MP, UribeVillarreal J, Hilario-Vargas J, Adrianzén RE. 2019. Características epidemiológicas de los traumatismos oculares en un instituto oftalmológico de referencia regional, Trujillo Perú, 2016 2017. Acta Med Peru 36: 281-286.

9. Dua HS, King AJ, Joseph A. 2001. A new classification of ocular surface burns. Brit J Ophtalmol 85: 1379-1383. doi: 10.1136/bjo.85.11.1379

10. Edwards RS. 1987. Ophthalmic emergencies in a district general hospital casualty department. Brit J Ophthalmol 71: 938-942. doi: 10.1136/bjo.71.12.938 
11. Gandaho HJ, Soumaila M, HoinsouHans I, Djrolo GM, Zevounou AA, Adeleye AO. 2016. Main neurosurgical pathologies in Benin Republic. J Neurosci Rural Pract 7(Suppl 1): S52S56. doi: 10.4103/0976-3147.196442

12. Geerling G, MacLennan S, Hartwig D. 2004. Autologous serum eye drops for ocular surface disorders. Brit J Ophthalmol 88:1467-1474. doi: 10.1136/ bjo.2004.044347

13. Girard B, Bourcier F, Agdabede I, Laroche L. 2002. Activité et épidémiologie d'un centre d'urgence en ophthalmologie. J Fr Ophtalmol 25: 701-711. doi: JFO-09-2002-25-7-0181-5512-101019ART6

14. [INO] Instituto Nacional de Oftalmología. s.f. Estadística, [Internet]. Disponible en: https://www.ino.gob.pe/estadistica/

15. Kanski J. 2008. Oftalmología clínica. $5^{\circ}$ ed. Barcelona, España: Elsevier. $816 \mathrm{p}$.

16. Ministerio de Salud. 2009. Guía clínica. Trauma ocular grave. Santiago de Chile: MINSAL. 38 p.

17. Montón-Echevarría J, Pérez Redondo S, Gómez Bajo GJ. 2007. Experiencia clínica en el empleo de factores de crecimiento autólogos obtenidos de plasma rico en plaquetas. Rev Latinoam Cir Plast 33: 155-162.

18. [MTPE] Ministerio de Trabajo y Promoción del Empleo. 2020. Boletín Estadístico Mensual: Notificaciones de accidentes de trabajo, incidentes peligrosos y enfermedades ocupacionales. $\mathrm{N}^{\circ}$ 12, año 09. [Internet]. Disponible en: https://www.gob.pe/institucion/mtpe/informes-publicaciones/1646255-boletinestadistico-mensual-notificaciones-deaccidentes-de-trabajo-incidentes-peligrosos-y-enfermedades-ocupacionales-n12-ano-09-edicion-diciembre-2020a

19. Nash EA, Margo CE. 1998. Patterns of emergency department visit for disorders of the eye and ocular adnexa. Arch Ophthalmol-Chic 116: 1222-1226. doi: 10.1001/archopht.116.9.1222
20. Nishida T, Nakamura M, Ofuji K, Reid TW, Mannis MJ, Murphy CJ. 1996. Synergistic effects of substance $\mathrm{P}$ with insulin-like growth factor-1 on epithelial migration of the cornea. J Cell Physiol 169: 159-66. doi: 10.1002/ ( S I C I ) 1097 - $4652(199610)$ 169:1<159::AID-JCP16>3.0.CO;2-8

21. Noble BA, Loh RS, MacLennan S, Pesudovs K, Reynolds A, Bridges LR, Burr J, et al. 2004. Comparison of autologous serum eye drops with conventional therapy in a randomised controlled crossover trial for ocular surface disease. Br J Ophthalmol 88: 647-652. doi: 10.1136/bjo.2003.026211

22. Sánchez H, Galindo A, Iglesias D, Galindo J, Fernández M. 2004. Estudio epidemiológico de las urgencias oftalmológicas en un hospital general. Arch Soc Esp Oftalmol 79: 71642662. doi: 10.4321/S0365-66912004000900004

23. Solans Pérez AM, Salgado AD, Ortega Molina JM, Chaves Samaniego MJ. 2015. Plasma enriquecido en plaquetas una alternativa como tratamiento de la patología oftalmológica. Annals d'oftalmologia 23: 4

24. Spector J, Fernández WG. 2008. Chemical, thermal and biological ocular exposures. Emerg Med Clin N Am 26: 125-136. doi: 10.1016/j.emc.2007.11.002

25. Tsubota K, Goto E, Fujita H, Ono M, Inoue H, Saito I, Shimmura S. 1999. Treatment of dry eye by autologous serum application in Sjogren's syndrome. Brit J Ophthalmol 83: 390-395. doi: 10.1136/bjo.83.4.390

26. Vercesi A, Atilio G, Echevarria $\mathbf{G}, \mathrm{Na}$ ves $A$, Decima $M$, Astorquia $J$, Burugos R, et al. 2009. Evaluación del uso tópico de factores de crecimiento derivados de plaquetas en el tratamiento de úlcera de córnea en conejos. Oftalmol Clin Exp 3: 23-28.

27. Young A, Cheng A, Ng H, Cheng L, Leung G, Lam D. 2004. The use of autologous serum tears in persistent corneal epithelial defects. Eye 18: 609614. doi: 10.1038/sj.eye.6700721 